\title{
Da Relevância dos Estudos Observacionais
}

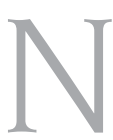

este número da RBR, um trabalho original reporta os primeiros resultados da experiência no manejo de pacientes portadores de artrite reumatóide em três importantes centros acadêmicos e de referência no Estado de São Paulo (Louzada-Junior et al., 2007).

Além de apresentar uma abordagem geral sobre o tratamento desses pacientes, $\mathrm{o}$ artigo levanta interessantes pontos para discussão. Considerando o atual acesso a terapias imunobiológicas no Estado mais rico da Federação, cabe refletir sobre a dificuldade na disponibilidade de serviços de reabilitação e terapia física. A rigor, não nos parece razoável supor que aspectos econômicos justifiquem essa situação. Cabe perguntar se existe uma responsabilidade do reumatologista em não enfatizar a indicação de terapia física ou alternativas nãofarmacológicas. Face à carência de evidências científicas que comprovem a eficácia de tais terapias, não haveria espaço para novas linhas de pesquisa nessa área, para além das iniciativas de pesquisa já existentes no País?

Numa época de reinado cada vez mais absoluto da medicina baseada em evidências, os estudos observacionais, sejam estudos transversais, retrospectivos ou mesmo de revisão de prontuários, aparentemente perdem valor diante de ensaios clínicos controlados randomizados (ECR). Entretanto, não obstante a necessidade de ECR para aplicação de novas terapias ou métodos, restrições na seleção de pacientes, por vezes, desviam os resultados daquilo que a "vida real" proporciona. Ressaltem-se ainda as limitações na avaliação de eventos adversos, observados por vezes apenas quando de estudos pós-comercialização.
Dessa forma, estudos observacionais têm a vantagem de reunir grande número de pacientes e, por vezes, melhor representar a "vida-como-ela-é". Acreditamos que ambos os processos, de estudos controlados e randomizados, associados a estudos observacionais, se complementam na formação do conhecimento, cujo objetivo final é a melhoria da qualidade de vida de quem busca tratamento.

Nesse ponto, o artigo supracitado vem se somar às outras experiências já relatadas, em artrite reumatóide e outras patologias, passando a se constituir em mais uma referência para estudos abordando nossa realidade. Experiências multicêntricas em curso no nosso país, algumas com interação internacional, como o GLADEL, GLADAR, GEPRO, e o Registro Brasileiro de Espondiloartropatias, contribuirão para a melhor compreensão da epidemiologia das doenças de interesse da reumatologia no nosso país. Acreditamos que esses resultados poderão melhorar a atenção à saúde. Não perderemos por esperar.

Francisco Airton Castro da Rocha

Doutor em Reumatologia, Professor Adjunto de Reumatologia, Faculdade de Medicina da Universidade Federal do Ceará (UFC)

Ricardo Machado Xavier

Doutor em Imunologia, Universidade de Shimane, Japão, Professor Adjunto de Reumatologia, Universidade Federal do Rio Grande do Sul (UFRS) 